\title{
ASSESSING FARM MANAGEMENT PRACTICES IN INDIAN FARMING: A REVIEW
}

\author{
Parvez Alam Khan \\ Research Scholar, PhD Research Centre, Presidency College, \\ Affiliated to Bangalore University, Bengaluru 560024, India
}

\section{Dr. Irshad Nazeer}

Associate Professor, Dept. of Management, Presidency College, Kempapura, Hebbal, Bengaluru, Karnataka 560024, India

\begin{abstract}
This study focuses on Indian farming and the farming practices that will improve the financial performance of the farming community and the measures that can be taken to enhance the farm fields' yields of Indian farmers. The study begins with the collection of statistics which are relevant to the financial growth of the farming sector of the chosen Indian states while noting the farming practices adopted by the farmers to improve their financial growth. It will then proceed to suggest more of a sustainable and more efficient productive farming strategy and identifying measures that will assist in the overall improvement in the farming sector.
\end{abstract}

Keywords Farm management practices, financial performance, agriculture, sustainable farming, commercial farming

Cite this Article: Parvez Alam Khan and Dr. Irshad Nazeer, Assessing Farm Management Practices in Indian Farming: a Review, Journal of Management, 6 (2), 2019, pp. 130-137.

http://www.iaeme.com/JOM/issues.asp?JType=JOM\&VType=6\&IType=2

\section{INTRODUCTION:}

India is an agro-based nation, yet the system surrounding the Indian agriculture is improper and overwhelmed by corruption; production and the economy associated with it is biased. These intricacies directly harm our farmers by causing them failure to obtain their possible earnings while subsequently are overburdened with debts and consequently heading towards suicide. These suicide incidents are counterproductive to our economy, causing a shortage of farmers, agricultural products and necessary food items on one hand and wastage to the energy resources on the other.

Indian Agriculture is still a critical contributor to raw materials, for many agro-based industries. The future of Indian agriculture seems to be technology-intensive. The current economy shows that one-fifth of the agricultural system in the Gross Domestic Product (GDP), is reduced from one-half of the GDP concerning the time of Independence of India in 1947. 
Development of modern and advanced technologies will be very eminently vital in achieving a higher rate of agricultural growth to avail and fulfil the needs of the increasing population. Agriculture is the pillar of India's economy. Rural households of more than 58\% depend upon agriculture (Planning Commission, 2012) because it is the primary source of income and living. But India is facing various problems in the agriculture sector, and this happens possibly because of a lack of governance, improper infrastructure, irrigation problems, corrupted mediators and similar issues (Hazell \& Ramasamy, 2009). The Indian Government is providing various beneficial Yojana's to the farmers but yet still, the proper contribution of multiple schemes are not provided to farmers even a suitable data on the agricultural sector is not available to the Indian Government, for example the data regarding the area of land being utilized for farming, or how much the final production of crops can be expected is not available, and due to this a proper implementation of various schemes has not been very successful (Cororaton, 1998).

\subsection{OBJECTIVES OF THE RESEARCH}

The following are the objectives of the research paper:

1 To review the literature on farm management and its impact on farm financial performances

2 To understand the various farm management practices adopted by the Indian farmers

3 To understand the various issues and challenges in farm management

\section{LITERATURE REVIEW}

India has made accelerated paces for the improvement in food production and the country is progressively becoming not only sufficient in the production of food but also exports to many other countries as well. However, the climate change has arisen as a significant menace to India's success in agro. Most of the Indian population relies on climate-sensitive sectors such as agriculture, forestry, and fishing, and thereby the livelihoods of pertaining to hundreds of millions of people, are at peril. The nation has already seen many conflicting impacts of climatic change on food production, transportation, storage, and distribution. The Increase in temperatures, erratic rainfall and extreme weather conditions, such: as extended droughts and floods, changing soil fertility, and new pest infestations are significant factors that has contributed to the agriculture and stunted dormant agricultural growth (Sarkar et al., 2019).

\subsection{Farm Management practices}

Better Management Practices (BMPs) for farming are a standardized set of farming practices, to ensure the environmental and financial sustainability, of the farming systems. The uniform implementation of these practices poses a challenge, if most of the farms, in a given region are small, i.e., in which covers a smaller area for cultivation. The overall rate of adoption was noted to be approximately $73 \%$, where BMPs were classified into six factors: optimized input supply, advanced management practices, routine support, social duty, group approach, culture-system related and similar methods (Sivaraman, 2019).

\subsubsection{Soil and water conservation practices}

Various moisture conservation techniques, like: mulching, weeding and tillage, are often employed to collect runoff rainwater, improving the yield of both, the seasonal and perennial crops. The enhancement in the growth of trees and plants even in the Indian desert because of the rainwater harvesting and in-situ conservation practice has also been observed. The ridge and furrow method was discovered to be one of the most efficient and effective methods of moisture storage, in the establishment of new forests. The moisture conservation technique has 
proved to be a benefiting factor for the arid ecosystem, in terms of forest creation and crop production, with higher socio-economic stability (Gupta, 1995).

Good rainfall, alone, does not automatically signify better crop production, as rain is not a credible measure for the retention of soil moisture, which is a prime factor, in plant growth. Instead of going for weather forecasting and rainfall prediction, soil moisture observation can be a more efficient decision-making tool for farmers. In conventional farming the relationship between rainfall and subsequent moisture retention is unpredictable. Generally, the rainwater evaporates or flows away through surface runoff if it is not conserved in time. The moisture level goes down, because of tillage and surface aeration (Horrigan et al. 2002).

A research project on in-situ moisture conservation has concluded that the crop yield became better due to the availability of moisture, at various stages of the crop's life cycle. Rainwater was harvested in-situ by usage of a compartmental bunding and ridge-furrow which locked water in the field by curbing runoff. As a result, the water is percolated into the soil. A portion of that water remains in the ground as a form of moisture, and the rest goes inside the soil and converts into groundwater. The utilisation of the farm manure and other materials from organic/natural resources improve the soil's health, in which develops the porosity and infiltration rate. Hence, in-situ soil and water conservation became effective (Patil \& Sheelavantar, 2004).

\subsubsection{Integrated pest management}

Despite the availability of multiple alternatives for controlling the pests of crops in India, pest management for better crop health does not seem to be successful in these fields, and the adoption of the pest management measures is low owing, to numerous socio-economic and other restraints (Kumar et al., 2018). Apart from the lack of awareness it was also, realised that a long prescription for pest management did not agree with the financial conditions of the farmers. This was because of, at part, of the segments stated by the pest management package or the prescriptions, thereby, involved some costs, which totalled to a significant figure in varying location, and additional factors, which was not financially viable. A method to experimentally quantify the components in terms of reduction of losses, while improving financial benefit was, therefore, thought up. Evidence was discovered, on the integrated management of biotic stresses of oilseeds that Brassica was inadequate, predominantly through the application of safer interventions, more so concerned with, input-based economics. Thus, the effect of plant-based extracts from biological control agents and chemical pesticides, singly and with integration in a study over multiple locations to make assessments of the seed yields and the economic benefits arising from some promising treatments of Indian mustard as a part of prioritized component-wise pest control strategy for the oilseed Brassica crop (Yadav et al., 2019).

\subsubsection{Technological advances in crop protection}

From the public safety standpoints, the unguarded and sudden, upscaled application of nanoparticles in agriculture, raises the concerns for Nanopesticides concerning food, water quality, farm workers and nontarget beneficial organisms given that, their use in the production and storage of crops is profitable (Kuniuki, 2001). Historically, farming was done with, decidedly, fewer chemicals and with more natural resources. During 1940s due to extensive floods and droughts, the alternates for quick plant protection was being researched, and the idea of the Green Revolution started evolving in many parts of the world. During the Green Revolution, extensive use of chemicals being used for crop protection and production. Realising the adverse impact on the environment and people, scientists and farmers started working on alternate technologies, which were eco-friendly for sustainable farming. Use of the biological 
control for pest management found its way in mainstream farming. Gradually, at present, there is a shift from macro technology to nanotechnology due to its precision and sustainability.

Nanotechnology has the ability to transform agriculture with new tools, by enhancing the ability of plants to absorb nutrients. Nanoparticles have interactions, at the molecular level, in living cells and Nanotechnology in agriculture, involves nanoparticles, so that, these particles impart several beneficial effects to the crop (Kotegooda and Munaweera, 2011). The utilization of nanoparticles in the growth of plants and for the control of plant diseases, is a more recent exercise, where nanoparticles are used as an additive (silver nanoparticles) and active ingredients $\left(\mathrm{TiO}_{2}\right)$ in solid and non-solid forms like lipids, polymers and emulsions (Shah and Belozerova, 2009). Researchers have also studied the impact of a combination of various nanoparticles on the crop. Many researchers examined the effect of mixtures of nano $\left(\mathrm{SiO}_{2}\right)$ and nano $\left(\mathrm{TiO}_{2}\right)$ on Soybean seed the Researchers discovered that the mixture of nanoparticles increases the nitrate reductase in Soybeans (Prasad et al., 2012).

\subsubsection{Organic farming}

The Post Green Revolution, efforts have been generated, only, towards higher crop production without consideration for soil health (Shiva, 1991). Now, when productivity growth has decreased, the concept of 'organic farming' is being reinforced to sustain long-term productivity. However, to implement the culture of organic farming, organic soil management is one of the most important criteria for which dairy farming is an essential component. Largescale conversion, to organic farming, requires bringing cows back to farms, to ensure organic manure supply (Anonymous, 2006). Successful planning on dairy farming, in the rural sector shall not only foster organic agriculture, but the improvement of farmers' economic profile shall also be an added benefit.

Organic farming has surfaced as one of the fastest growing sectors of environment-friendly sustainable agriculture. Being hazard free, the demand for organic food is unwaveringly arising both in the developed and developing countries with an annual average growth rate of 20-25\% (Romesh et al. 2005). Organic farming, which depends on "biologically driven nutrients' instead of synthetic fertilisers, utilises management of soil organic matter to enhance physical, chemical and biological properties of soil. This agricultural practice helps to minimise food chains associated with health hazards and attaining a closed nutrient cycle, a key factor for sustainable agrarian production (Cardelli et al. 2004).

\subsubsection{Modern Agriculture biotechnology}

The prologue and scope of Genetically Modified (GM) crops have become one of the more critical technological changes currently taking place in the world. While the potential of this technology is still debatable, the farmers' order for GM seeds has continued to proliferate. In 2007, about 114 million hectares were grown globally with GM crops, with over $40 \%$ of this area found in developing countries (James, 2007). One of the most widely adopted GM technologies in developing countries is Bacillus thuringiensis $(\mathrm{Bt})$ cotton, which makes the plant resistant to certain insect pests, especially cotton bollworms. Among the beneficial impacts of Bt cotton, significant yield increases and pesticide reductions have been reported for different countries (Thirtle et al., 2003). As the technology is divisible and pest pressure relevant across farm sizes, it is believed to be scale neutral, so that, both, small and large farms can benefit (Qaim, 2005). 


\section{MANAGEMENT PRACTICES AND THEIR IMPACT ON FINANCIAL PERFORMANCE}

As argued, by Rougoor et al. (1998), to understand the importance of farm management, it is imperative to measure the farm performance and management over time. Because a primary goal of farm management is to achieve superior long-term financial performance, there is a persisting need to investigate the relationship between farm management practices and longterm financial performances. The Effective production has been revealed to be a fundamental factor affecting the farm's financial performance.

Farmers are using Internet applications, to perform tasks, such as: tracking prices, accessing agricultural information, assessing information from government agencies, and online recordkeeping with increasing enthusiasm (Mishra et al., 2008). Internet usage could serve to speed up the diffusion of innovation deemed appropriate for small farm businesses. Recently, Sila (2013) found that many variables ranging from farm size and farm type to the variables, such as pressure from competitors, network reliability, scalability, top management support, and trust, affecting the farms' decision to adopt business-to-business electronic commerce. Small farming businesses (defined as small farm business households where the operator's primary occupation is farming) are a subject of interest in recent agricultural economics and agribusiness literature, mainly, how best can they strategically manage the farm business to remain viable in the marketplace.

\section{PRACTICES AND POLICIES TO IMPROVE THE SUSTAINABLE FINANCIAL PERFORMANCE OF THE AGRICULTURAL INDUSTRY}

Replacement of toxic pesticides by other less harmful products is considered an improvement only if the need for these products has also been established through an ecological field assessment. Mere substitution of synthetic pesticides with bio control agents or other technologies such as transgenic cotton thus is unlikely to become a definitive solution to sustain agricultural productivity, unless these new technologies are paired with educational programmes for farmers, spray operators, hired workers, and family members who also work on the crop. The cultivation of the genetically modified bollworm-resistant Bt cotton was recently (2002) authorized in India. Although increased yields and profits, along with reduced pesticide applications have been credited to its introduction (Huang et al., 2013), also many cases of poor performance have been reported, particularly in Andhra Pradesh (Kranthi et al., 2005). Considering the severe degree of acute pesticide poisoning affecting cotton growers in the studied area (Mancini et al., 2005), the promotion of IPM (Integrated Pest Management) through implementation of FFSs (Farm Field Schools) on a larger scale is a advisable to mitigate the severe consequences that the heavy use of pesticides has caused to people's health, and especially to women's health. However, the costs of FFSs compared to other approaches have been debated (Quizon et al., 2001) and can be seen as a factor limiting large-scale public investment in FFSs. As yet, few evaluations have attempted to quantify the development benefits of FFSs beyond the technical gains, such as human capacity, social capital, and institutional building (Mancini et al., 2005).

\section{ISSUES AND CHALLENGES IN FARM MANAGEMENT}

Indian agriculture is highly intensive, mostly small to marginal farmers, diverse agro-ecologies \& production environments, several crops /cropping systems and presently showing concerns of yield stagnation or decline. The factor productivity of prime inputs is going down. Soil fertility, mostly secondary and micronutrients, is going down. There is a need to identify options for sustainable agriculture by ensuring safeguarding the environment. There exists a large yield gap (attainable minus actual yields) for principal crops, and we need to identify various biotic 
and abiotic stresses responsible for this gap. Newer insects/pests are appearing, and we need to check the yield losses due to insects/pests. Rapid land use and cover change is also the primary concern, and we need to take care of the interests of the small/marginal farmers. Enhanced industrial growth and the increased population are causing matters related to soil, air and water pollution. Land degradation viz. decline in soil fertility, increased soil salinity/water-logging, decreased soil biological activity, increased solid wastes, are prime concerns and raises the need for proper management for agri-sustenance. Groundwater table decline in most of the districts is noticed. There is a need to sequester carbon content in our soils, could be through crop residue incorporation in the ground, adoption of suitable land preparation/tillage options, organic farming. There is a need to develop a regional platform for operational agri-knowledge dissemination and crop production monitoring and yield forecasting (Kalra \& Kumar 2019).

\section{CONCEPTUAL FRAMEWORK AN INTRODUCTION AND DESCRIPTION OUTLINING POTENTIAL CAUSES OF EXISTING CHALLENGES TO THE INDIAN AGRICULTURAL SECTOR AND DESCRIBES POTENTIAL ACTIONS THAT WILL REPLACE THESE CHALLENGES}

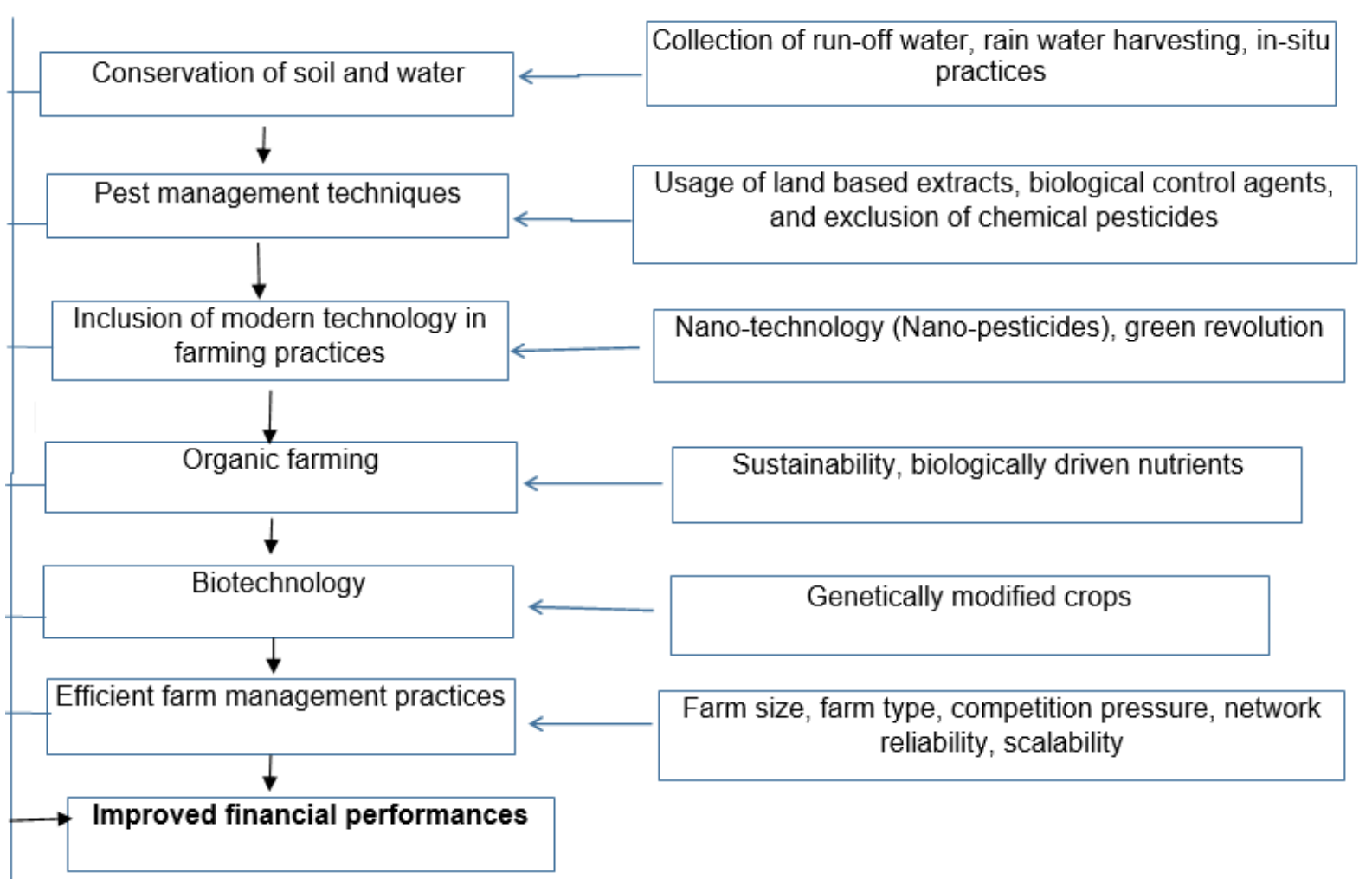

Figure 1 Conceptual Framework

\section{FINDINGS AND DISCUSSION}

Thus, it has been found in this review paper that the primary reason that even though India is majorly dependent on agriculture as a source of food and economic development of the nation, the farmers and farming techniques are still at the stage where they need development despite the farm management measures adopted. The adoption of these measures is relatively low due to the lack of awareness. There has been the introduction of organic as well as sustainable farming among the Indian farmers, but the reach has not spread broadly yet. 
To conclude, a certain number of measures and practices need to be adopted by Indian farmers that seem acceptable by the farmers and more comfortable to be incorporated into their farming routines, while not tampering with the environment. This paper thus attempts to suggest some of these sustainable practices that could help the farmers to increase their financial performance.

\section{REFERENCES}

[1] Anomynous, Can Organic Farming Feed Us All? World Watch Magazine 2006 May- June; 19 (3), 2006

[2] Cardelli, R., Levi-Minzi, R., Saviozzi, A., \& Riffaldi, R, Organically and conventionally managed soils: biochemical characteristics. Journal of Sustainable Agriculture, 25, 2004, pp 63-74.

[3] Chen, R., Huang, J., \& Qiao, F, Farmers' knowledge on pest management and pesticide use in Bt cotton production in china. China Economic Review, 27, 2013, pp 15-24.

[4] Cororaton CB, Rates of return to R\&D investment in the Philippines. Philippine Institute for Development Studies, Makati City, 1998

[5] Gupta G. N, "Rain-Water Management for Tree Planting in the Indian Desert", in: Journal of Arid Environments, 31(2), 1995, pp 219-35, https://doi.org/10.1006/jare.1995.0062 (24 September 2016)

[6] Hazell P, Ramasamy C, The green revolution: reconsidered. The Johns Hopkins University Press, Baltimore, 242, 2009

[7] Horrigan, L., Lawrence, R. S., \& Walker, P, How sustainable agriculture can address the environmental and human health harms of industrial agriculture. Environmental health perspectives, 110(5), 2002, pp 445-456.

[8] James, C, Global status of commercialized biotech/GM crops: 2007. ISAAA Brief No. 37Ithaca: ISAAA, 2007

[9] Kalra, N., \& Kumar, M, Simulating the Impact of Climate Change and its Variability on Agriculture. In Climate Change and Agriculture in India: Impact and Adaptation Springer, Cham, 2019, pp. 21-28

[10] Kranthi, K. R, Insecticide resistance-monitoring, mechanisms and management manual. Central Institute for Cotton Research, PB, (2), 2005, pp 49-87.

[11] Kumar, A., Nemade, P. W., Sharma, R., Tanwar, R. K., Chattopadhyay, C., Wanjari, S. S., $\&$ Rathod, T. H, Statistical forewarning models for sucking pests of cotton in Maharashtra. Journal of Agro meteorology, 20(1), 2018, pp 62-65.

[12] Lanjouw, P., Quizon, J., \& Sparrow, R, Non-agricultural earnings in peri-urban areas of Tanzania: evidence from household survey data. Food policy, 26(4), 2001, pp 385-403.

[13] Mancini F., Van Bruggen A.H.C., Jiggins J.L.S., Ambatipudi A.C., and Murphy H. Acute pesticide poisoning among female and ma^le cotton growers in India. Int J Occup Environ Health 2005: 11(3): 221-232.

[14] Mishra, A., Salokhe, V.M., Seedling characteristics and the early growth of transplanted rice under different water regimes. Exp. Agric. 44, 2008, pp 1-19

[15] Mishra, M., Dashora, K., Srivastava, A., Fasake, V. D., \& Nag, R. H, Prospects, challenges and need for regulation of nanotechnology with special reference to India. Ecotoxicology and environmental safety, 171, 2019, pp 677-682.

[16] Pankhurst, C.E., Hawke, B.G., McDonald, H.J., Kirkby, C.A., Buckerfield, J.C., Michelsen, P., O'Brien, K.A., Gupta, V.V.S.R. and Doube, B.M., Evaluation of soil biological properties as potential bio indicators of soil health. Australian Journal of Experimental Agriculture, 35(7), 1995, pp 1015-1028. 
[17] Patil, S. L., \& Sheelavantar, M. N, Effect of cultural practices on soil properties, moisture conservation and grain yield of winter sorghum (Sorghum bicolar L. Moench) in semi-arid tropics of India. Agricultural water management, 64(1), 2004, pp 49-67.

[18] Patil, S.L.; Sheelavantar, M.N, Effect of Cultural Practices on Soil Properties, Moisture Conservation and Grain Yield of Winter Sorghum (Sorghum bicolar L. Moench), in: Agricultural Water Management, 64, 2004

[19] Planning Commission. Document of Eleventh Five Year Plan, Inclusive Growth, Vol.1, (Chap. 1, p 1), and 2. Agriculture, Rural Development, Industries, Services and Physical Infrastructure, vol 4 (Chap. 1, p 1 and Chap. 4, p 79). Oxford University Press, New Delhi., 2007

[20] Prasad, T.N.V.K.V., Sudhakar, P., Sreenivasulu, Y., Latha, P., Munaswamy, V., Reddy, K.R., Sreeprasad, T.S., Sajanlal, P.R., Pradeep, T, Effect of nanoscale zinc oxide particles on the germination, growth and yield of peanut. J. Plant Nutr. 35 (6), 2012, pp 905-927.

[21] Qaim, M, Agricultural biotechnology adoption in developing countries. American Journal of Agricultural Economics, 87(5), 2005, pp 1317-1324.

[22] Rougoor, C. W., Trip, G., Huirne, R. B., \& Renkema, J. A, How to define and study farmers' management capacity: theory and use in agricultural economics. Agricultural economics, 18(3), 1998, pp 261-272.

[23] Romesh, P., Singh, M., \& Subba rao, A, Organic farming: its relevance to the Indian context. Current Science, 88, 2005, pp 561-568.

[24] Sarkar, A., Dasgupta, A., \& Sensarma, S. R, Climate Change and Food Security in India: Adaptation Strategies and Major Challenges. In Sustainable Solutions for Food Security. Springer, Cham, 2019, pp. 497-520

[25] Shah, V., Belozerova, I, Influence of metal nanoparticles on the soil microbial community and germination of lettuce seeds. Water Air Soil Pollut. 197 (1-4), 2006, pp 143-148.

[26] Shiva V. The Violence of the Green Revolution: Third World Agriculture Ecology and Politics. Malaysia: Third world network; 1991, 1-257.

[27] Sila, I, "Factors affecting the adoption of B2B e-commerce technologies." Electronic Commerce Research, Vol. 13, No. 2, 2013, pp. 199-236.

[28] Sivaraman, I., Krishnan, M., \& Radhakrishnan, K, Better Management Practices for sustainable small-scale shrimp farming. Journal of Cleaner Production, 214, 2019, pp 559572.

[29] Thirtle, C., Beyers, L., Ismael, Y., \& Piesse, J, Can GM-technologies help the poor? The impact of Bt cotton in Makhathini Flats, KwaZulu-Natal. World development, 31(4), 2003, pp 717-732.

[30] Yadav, M.S., Godika, S., Yadava, D.K., Ahmad, N., Mehta, N., Bhatnagar, K., Agrawal, V.K., Kumar, A., Thomas, L. and Chattopadhyay, C, Prioritizing components of package of integrated pest management in Indian mustard (Brassica juncea) in India for better economic benefit. Crop Protection, 2019 